\title{
CORRESPONDENCE
}

\section{Screening criteria for NICU admissions: decisions require developing trust}

Zulfiker Ali in his commentary focuses on the need for developing selection criteria for preterm infants for admission to neonatal intensive care units (NICUs) (1). He makes the argument that in the absence of clear guidelines, many NICU admissions occur which are essentially futile. In his opinion, a national level policy to delineate acceptable criteria for NICU admissions could help address this problem. Ali also highlights the high cost of NICU care for parents, as most NICUs are in the private sector, besides the need to counsel parents and involve them in decision making.

In my opinion, it would perhaps be best to keep the medical futility criteria and discussions around costs of NICU care for parents/families separate rather than integrate them into a single screening policy for NICU admissions.

Once the aforementioned (medical futility) criteria are evolved, and a preterm infant is born, there could be two possible scenarios which could arise:

a) On the birth of a preterm infant, initially a discussion about financial aspects of NICU care with the parents occurs; if the parents have the required resources, then the medical futility criteria for NICU admissions are applied, and a decision is made on NICU admission.

b) On the birth of a preterm infant, initially the medical futility criteria are applied; if NICU care would be clinically indicated, then a discussion about financial implications of NICU care occurs with parents, and a decision is made on NICU admission.

The second option seems preferable as the initial screen is medical eligibility rather than a cost consideration. However, even this choice would be ethically problematic as sometimes preterm infants who would benefit from NICU care would not be able to get it as their parents cannot afford it. The treating physician might then have to let the preterm baby die (unless alternate mechanisms can be mustered, such as a philanthropic grant or the hospital writing off the costs). This links to the important equity issue of lack of high quality medical care for those who are financially underprivileged in India.
There are few data in the country about the cost of NICU care. A study from 1998 found average daily hospital charges per day for infants in NICU to be Rs 727 among survivors and Rs 1,857 among non-survivors in a tertiary hospital in Chennai (2). A more recent study published in 2005 found the cost of NICU care in a community trust hospital in Agra to be Rs 400500 a day for every newborn (3). The cost currently, especially in corporate hospitals, must be much higher.

Conversations about medical futility, prognosis as well as monetary requirements of care are not easy, especially when dealing with parents of preterm infants. Healthcare providers in such circumstances would need to be honest as well as particularly sensitive and compassionate. Involving trained medical social workers, as well as non-governmental organisations such as patient support groups would be one way of ensuring that decisions taken in such difficult times are in an atmosphere of trust, transparency and support. The process would benefit from the advice of hospital clinical ethics committees (often rare in our context), as suggested by Ali (1).

Since time is a major factor in situations when intensive care is required, hospitals should set up mechanisms in advance to promote shared decision making in an atmosphere of trust between parents and healthcare providers.

Anant Bhan, Independent Researcher, Bioethics and Public Health, Flat 405, Building A-11, Planet Millennium, Aundh Camp, Pune 411027 INDIA email: anantbhan@gmail.com

\section{References}

1. Ali Z. Selection criteria in the NICU: who should get effective critical care? Indian J Med Ethics .2009 Apr-Jun;6(2):103-4. Cited in PubMed; PMID 19517656.

2. Shanmugasundaram R, Padmapriya E, Shyamala J.Cost of neonatal intensive care. Indian J Pediatr .1998;65:249-55. Cited in PubMed; PMID 10771970.

3. Garg P, Krishak R, Shukla DK. NICU in a community level hospital. Indian J Pediatr. 2005;72(1):27-30. Cited in PubMed; PMID 15684444.

\section{Correction}

In the letter by Nausheen Saeed and Sarwat Nasreen (Antibacterial products: myth or reality? Indian J Med Ethics 2009; 6(4): 170-1) Dr Sarwat Nasreen's name was inadvertently omitted and Dr Nausheen Saeed's affiliation was incorrect. The correct details are as follows: Nausheen Saeed, general surgeon, and Sarwat Nasreen, dermatologist, Ziauddin University, Karachi, PAKISTAN. 